\title{
Structure and Evolution of the Smith-Magenis Syndrome Repeat Gene Clusters, SMS-REPs
}

\author{
Sung-Sup Park, ${ }^{1,5,6}$ Paweł Stankiewicz, ${ }^{1,5}$ Weimin Bi, ${ }^{1}$ Christine Shaw, ${ }^{1}$ \\ Jessica Lehoczky, ${ }^{4}$ Ken Dewar, ${ }^{4}$ Bruce Birren, ${ }^{4}$ and James R. Lupski ${ }^{1,2,3,7}$ \\ Departments of ${ }^{1}$ Molecular and Human Genetics and ${ }^{2}$ Pediatrics, Baylor College of Medicine, ${ }^{3}$ Texas Children's Hospital, \\ Houston, Texas, 77030, USA; ${ }^{4}$ Whitehead Institute for Biomedical Research/MIT Center for Genome Research, \\ Cambridge, Massachusetts 02141, USA
}

\begin{abstract}
An 4-Mb genomic segment on chromosome 17p11.2, commonly deleted in patients with the Smith-Magenis syndrome (SMS) and duplicated in patients with dup(17)(p1l.2p11.2) syndrome, is flanked by large, complex low-copy repeats (LCRs), termed proximal and distal SMS-REP. A third copy, the middle SMS-REP, is located between them. SMS-REPs are believed to mediate nonallelic homologous recombination, resulting in both SMS deletions and reciprocal duplications. To delineate the genomic structure and evolutionary origin of SMS-REPs, we constructed a bacterial artificial chromosome/P1 artifical chromosome contig spanning the entire SMS region, including the SMS-REPs, determined its genomic sequence, and used fluorescence in situ hybridization to study the evolution of SMS-REP in several primate species. Our analysis shows that both the proximal SMS-REP $(\sim 256$ $\mathrm{kb})$ and the distal copy $(\sim 176 \mathrm{~kb})$ are located in the same orientation and derived from a progenitor copy, whereas the middle SMS-REP $(\sim 241 \mathrm{~kb})$ is inverted and appears to have been derived from the proximal copy. The SMS-REP LCRs are highly homologous (>98\%) and contain at least 14 genes/pseudogenes each. SMS-REPs are not present in mice and were duplicated after the divergence of New World monkeys from pre-monkeys 40-65 million years ago. Our findings potentially explain why the vast majority of SMS deletions and dup(17)(p11.2p11.2) occur at proximal and distal SMS-REPs and further support previous observations that higher-order genomic architecture involving LCRs arose recently during primate speciation and may predispose the human genome to both meiotic and mitotic rearrangements.
\end{abstract}

Smith-Magenis syndrome (SMS) is caused in $>90 \%$ of cases by a common deletion of an $\sim 4-\mathrm{Mb}$ gene-rich genomic segment in $17 \mathrm{p} 11.2$. Recently, the same chromosome region has been shown to be duplicated in patients with the reciprocal chromosome duplication, dup(17)(p11.2p11.2) (Chen et al. 1997; Potocki et al. 2000). Physical mapping studies have shown that the SMS-common-deletion interval is flanked by large ( $200 \mathrm{~kb}$ ), highly homologous, low-copy repeat (LCR) gene clusters termed SMS-REPs (Chen et al. 1997). The proximal and distal SMS-REPs likely act as substrates for nonallelic homologous recombination (NAHR; also known as unequal crossing-over), resulting in both common deletions and reciprocal duplications of the same chromosome segment. A third copy, the middle SMS-REP, has been mapped in $17 \mathrm{p} 11.2$ between the proximal and distal SMS-REPs (Chen et al. 1997).

The chromosome $17 \mathrm{p} 11.2$ genomic region is involved in several other rearrangements. Isodicentric chromosomes $\operatorname{idic}(17)(p 11)$, with breakpoints mapping within or just adjacent to the SMS critical region, have been identified in various hematological malignancies, including chronic myeloid leukemia, and in solid tumors, such as childhood primitive neuroectodermal tumors (Fioretos et al. 1999; Scheurlen et al.

\footnotetext{
${ }^{5}$ These authors contributed equally to this work.

6Present address: Department of Clinical Pathology, Seoul National University Hospital, Seoul 110-744, South Korea. ${ }^{7}$ Corresponding author.

E-MAIL jlupski@bcm.tmc.edu; FAX (713) 798-5073.

Article and publication are at http://www.genome.org/cgi/doi/10.1101/ gr.82802.
}

1999). Chromosome amplifications within $17 \mathrm{p} 11.2$ have been described in patients with osteosarcoma and leiomyosarcoma (Tarkkanen et al. 1995; Otaño-Joos et al. 2000). In medulloblastomas, an aberrant hypermethylation of the major breakpoint cluster region in $17 \mathrm{p} 11.2$ has been proposed to be an additional genomic feature responsible for the chromosomal fragility (Frühwald et al. 2001). These data, together with identified somatic mosaicism for SMS deletions (Zori et al. 1993; Juyal et al. 1996), indicate that the presence of unique genome architecture features, including highly homologous SMS-REPs, makes the chromosome 17p11.2 a highly unstable region in the human genome, prone to both meiotic and mitotic rearrangements.

To delineate the genomic structure and evolution of the SMS-REPs, we constructed and sequenced a complete bacterial artificial chromosome/P1 artifical chromosome (BAC/PAC) contig. Based on genomic sequence analysis, we elucidated the size and the orientation of each SMS-REP, the extent of homology among the SMS-REPs, genes within the SMS-REPs, and here provide a model for the evolution of SMS-REPs. Sequence-based structural analysis of the SMS-REPs is essential to determine the molecular mechanism of chromosome rearrangements in SMS, as well as other genomic disorders (Lupski 1998). These studies add to a growing body of evidence that implicate genome architecture in DNA rearrangements responsible for genomic disorders (Lupski 1998; Mazzarella and Schlessinger 1998; Ji et al. 2000; Shaffer and Lupski 2000; Emanuel and Shaikh 2001; Stankiewicz and Lupski 2002). 


\section{RESULTS}

Aligning BAC Genomic Clones to Specific SMS-REPs by cis-Morphism Analysis and DNA Fingerprinting

The identification of genomic clones specific to an individual SMS-REP was possible due to a limited number of sequence differences among them, which we called cis-morphisms. Cismorphisms refer to sequence variation among nonallelic, highly similar sequence copies on the same chromosome. This term has been proposed to distinguish from polymorphisms resulting from variation between sequences on different chromosome homologs (alleles; Boerkoel et al. 1999). We identified SMS-REP-specific cis-morphisms using Southern blotting with genomic DNA and BAC clones as targets and compared the hybridization band patterns with those of established SMS-REP-specific yeast artificial chromosome (YAC) clones (912D7 and 567A2 for distal SMS-REP; 907E8 and 126H9 for proximal SMS-REP; 951G11 for middle SMS-REP) that were anchored with flanking unique sequences (Chen et al. 1997).

We documented previously that SMS-REPs contain at least four genes or pseudogenes (CLP, TRE, SRP, and KER, a keratin gene cluster) by sequence skimming of SMS-REPspecific cosmid clones (Chen et al. 1997). By utilizing probes from these genes in Southern analysis of genomic DNA and YAC clones anchored by flanking unique sequences, we have detected cis-morphisms that serve as unique identifiers to each specific SMS-REP. Multiple restriction enzyme digestions of large-insert genomic clones were utilized and enabled several cis-morphisms to be identified (Fig. 1; Table 1). Using $C L P, T R E$, and $S R P$ sequences as probes on a BAC genomic library we identified $>50$ SMS-REP-like BAC clones. The $C L P$ probe was a 1.1-kb HindIII fragment of the cDNA clone 41G7A (Chen et al. 1997), and TRE and SRP probes were amplified by 3'TRE and SRP primers, respectively. Cross-hybridizing fragments were then analyzed for SMS-REP specific cis-morphisms to uniquely identify to which SMS-REP (proximal, middle, or distal) each BAC clone mapped. Independently, all SMS-REP cross-hybridizing BAC clones were subjected to DNAfingerprinting analysis. The restriction patterns of the majority of these clones were highly similar, although minor differences allowed the BACs to be grouped into contigs. Fingerprint analysis was combined with hybridization analyses to select minimal clone sets for genomic sequencing.

\section{Generation of the BAC Contigs Spanning the SMS-REPs}

We collected BAC clones identified by hybridization screening of the RPCI-11 library and by computational methods using BLAST searches. Fifty-eight clones were assigned to individual SMS-REPs by cis-morphisms and DNA fingerprinting, and we constructed BAC contigs spanning the three individual SMS-REPs (Fig. 2). A minimal-tiling path of assigned BAC genomic clones, selected using the combined results of hybridization and fingerprinting analyses, was chosen for sequence analysis.

The mapping of the genomic BAC clones to the SMS-REP region in $17 \mathrm{p} 11.2$ was further confirmed by fluorescence in situ hybridization (FISH). Metaphase FISH analysis using the SMS-REP BAC clones displayed hybridization to the $17 \mathrm{p} 11.2$ region, whereas interphase FISH analysis showed three hybridization signals for each chromosome (one per chromatid for each of the three SMS-REP copies in this G2 interphase nucleus; Fig. 3). Although FISH analysis can identify SMS-REP

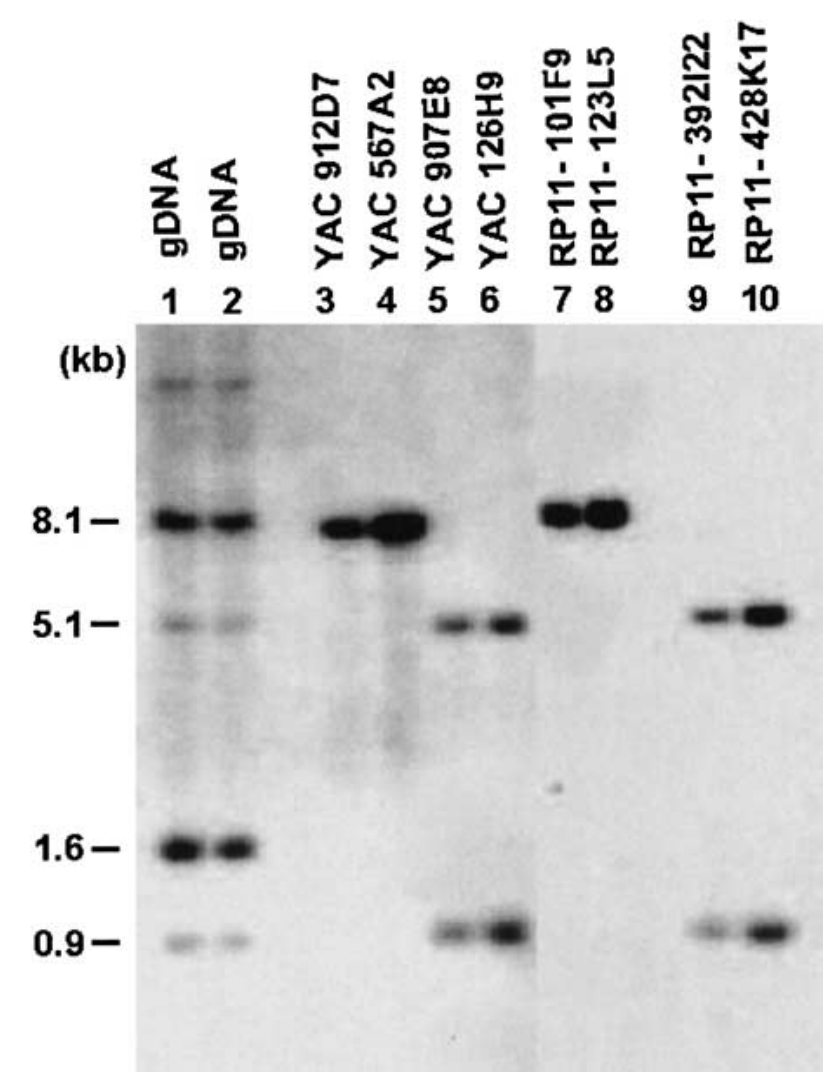

Figure 1 An example of a cis-morphism among three SMS-REPs. Southern blotting with CLP CDNA probe on HindllI-digested largeinsert genomic clones revealed an 8.1-kb band for the distal SMS-REP (lanes 3 and 4 for yeast artificial chromosomes [YACs]; lanes 7 and 8 for bacterial artificial chromosomes [BACs]) and $5.1 \mathrm{~kb}$ and $0.9 \mathrm{~kb}$ for the proximal SMS-REP (lanes 5 and 6 for YACs; lanes 9 and 10 for BACs). Hybridization to total genomic DNA (gDNA in lanes 1 and 2) reveals additional cross-hybridizing bands, which map to different genomic locations.

cross-hybridizing genomic sequences and distinguish three copies in 17p11.2, it cannot determine from which specific individual SMS-REP the signal arises. Therefore, cell lines from patients with selected $17 \mathrm{p} 11.2$ deletions were examined by FISH to further confirm BAC localization to the SMScommon-deletion region.

\section{Analysis of the Structures and the Sequences of Three SMS-REPs in 17p11.2}

Sequencing of the genomic clones in the minimal-tiling paths was performed at the Whitehead Institute/MIT Center for Genome Research. Sequences of two additional PAC clones, RP1-48J14/AL353996 and RP1-37N07/AL353997, were downloaded from the NCBI web site (http:// www.ncbi.nlm.nih.gov/). We thus analyzed genomic sequence spanning each individual SMS-REP. Based on the sequence information, a structural map of the SMS-REPs was constructed (Fig. 4) and analyzed for size and orientation of each SMS-REP, the extent of homology among the SMS-REPs, and gene content within the SMS-REPs.

The proximal SMS-REP is the largest, $\sim 256 \mathrm{~kb}$ (probably 255,808 bp; np 50,751 in RP11-121A13/AC008088 and np 4,010 in RP11-434D2/AC015818), and contains 14 genes/ 
Table 1. Cis-Morphisms Between SMS-REPs and the Related Structures. (Sizes in kb)

\begin{tabular}{|c|c|c|c|c|c|}
\hline Probe & $\begin{array}{l}\text { Restriction } \\
\text { enzymes }\end{array}$ & $\begin{array}{c}\text { Distal } \\
\text { SMS-REP }\end{array}$ & $\begin{array}{c}\text { Middle } \\
\text { SMS-REP }\end{array}$ & $\begin{array}{l}\text { Proximal } \\
\text { SMS-REP }\end{array}$ & $\begin{array}{l}\text { Other } \\
\text { sites }\end{array}$ \\
\hline$C L P$ & Hind III & $\underline{8.1}$ & $(-)$ & $\underline{5.1}, \underline{0.9}$ & $1.6,1.4$ \\
\hline \multirow[t]{3}{*}{ TRE } & Hind III & $\overline{14}$ & $8.5,5.3$ & 14 & 7 \\
\hline & Xbal & 11,7 & $11, \overline{7}$ & $11, \underline{4.3}$ & 15,9 \\
\hline & Pstl & $8,2.4$ & $8,4.1$ & $8, \overline{2.4}$ & 7 \\
\hline \multirow[t]{3}{*}{$S R P$} & Pvull & 2.3 & 2.3 & 0.8 & 14 \\
\hline & Rsal & 1.3 & 2.2 & $\overline{2.2}$ & $4.5,4.8$ \\
\hline & Taql & 4.1 & 4.5 & 4.1 & \\
\hline
\end{tabular}

Underlined numbers represent the bands unique to each SMS-REP.

pseudogenes. Based on flanking markers P836L9-5' and R193 (Fig. 2), the distal-proximal orientation of proximal SMS-REP is from SRP to CLP (Figs. 2, 4). The distal SMS-REP is 176,482 bp (np 10,612-187,093 in RP11-219A15/AC022596). Distal SMS-REP-flanking markers $92 B 11-R$ and $315 G 18-R$ showed that the distal SMS-REP is in the same SRP-CLP orientation. Therefore, proximal and distal SMS-REP represent direct repeats within 17p11.2. The markers SHMT and 484D23-R (Fig. 2) flanking middle SMS-REP (241 kb; probably $240,806 \mathrm{bp}, \mathrm{np}$ 42,370 in RP11-448D22/AC105100, and np 53,872 in RP137N07) showed that it is inverted with respect to proximal and distal SMS-REPs.

There are four regions of high homology between the proximal and the distal SMS-REPs (A, B, C, and D regions in Fig. 4). The sum of these high-sequence-similarity regions is $\sim 170 \mathrm{~kb}(169,905 \mathrm{bp})$, and the homology is greater than $98 \%$, with the exception of the D region (>95\%). The largest conserved segment (region A in Fig. 4 ) is $\sim 126 \mathrm{~kb}$ in size. Two large sequence blocks (between $\mathrm{A}$ and $\mathrm{B}$, and $\mathrm{C}$ and $\mathrm{D}$ ) in the proximal SMS-REP are absent in the distal SMS-REP. Two smaller blocks, flanking areas of the B region in the distal SMS-REP, are absent in the proximal SMS-REP.

At least 14 genes/pseudogenes were identified in SMSREPs and are summarized in Table 2 and Figure 4 . Two potential genes in the SMS-REPs include KIAA0565 and

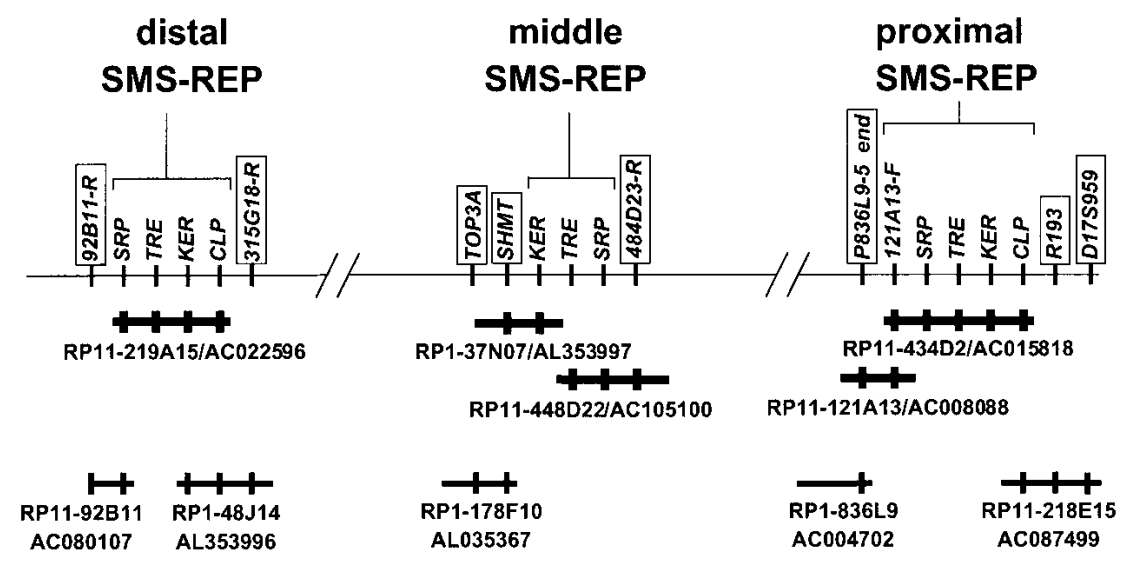

Figure 2 Bacterial artificial chromosome/P1 artificial chromosome (BAC/PAC) contig map spanning three SMS-REPs. Thick bold lines represent minimal-tiling-path, large-insert clones utilized for genomic finished sequence of SMS-REPs. Clones are designated with their clone name and their GenBank accession number. Markers in boxes represent SMS-REP-flanking sequences used to determine SMSREP orientations. Final orientation was determined by the construction of a complete BAC/PAC contig spanning the common deletion (Bi et al. 2002).
FLJ11800. The remaining genes appear to represent pseudogenes or pseudogene-like structures (UPF3A, LGALS9, SRP68, TL-132, NOS2A, MIP, KER cluster, USP6 [also known as TRE], $C L P$, and several expressed sequence tags: BG108241, AIG53154, AW977532, AL138090, AI913336, BF223454, $A W 469705, A L 136790, A A 405442)$. Importantly, sequence analysis confirmed the presence of all four genes/pseudogenes (SRP, KER, TRE, and CLP) previously identified within SMSREPs (Chen et al. 1997). Interestingly, many (7 of 14) of the genes/pseudogenes also map to the long arm of chromosome 17 (Table 2). Some parts of the gene sequences are repeated (e.g., a part of $T L-132$ sequence; $n p$ 4173-4326 of AJ012755 is duplicated and inverted). As predicted by previous hybridization studies, no CLP sequence was found in the middle SMS-REP, and the distal SMS-REP is devoid of two genomic fragments containing LGALS9, MIP, and USP6 (Fig. 4). In addition, BLAST analyses identified that an $\sim 2.3$-kb UPF3A gene, present in proximal and distal SMS-REPs, is absent in the middle SMS-REP. Interestingly, adjacent ( $400 \mathrm{bp})$ to this middle SMS-REP-specific deletion, a 1838-bp insertional duplication from chromosome 15q26.1 was identified (Fig. 4). BLAST analysis revealed that the overall similarity among SMS-REP-homologous segments is 98\% identical, indicating that SMS-REPs can likely act as substrates for NAHR, resulting in both deletions and reciprocal duplications of the same chromosome segment.

\section{Fragments of SMS-REPs Are Also Located Outside the SMS Region}

DNA-fingerprinting analysis of $C L P$ cross-hybridizing $\mathrm{BAC}$ genomic clones indicated several distinct contigs, two of which were mapped to proximal and distal SMS-REPs by cis-morphism analysis. To map other CLP genes/pseudogenes in the human genome, we used the clones from the unique BAC contigs that did not map to proximal or distal SMS-REPs as probes in FISH mapping studies. The majority of these BACs mapped to both chromosome $17 \mathrm{p} 11.2$ and $16 \mathrm{qter}$, indicating the presence of a CLP gene on chromosome $16 \mathrm{q} 24$.

FISH analysis using SMS-REP BAC clones (distal SMS-REP RP11219A15/AC022596, middle SMS- 
Park et al.

REP RP11-158M20/AC023401, and proximal SMS-REP RP11434D2/AC015818) as probes revealed strong hybridization signals on metaphase chromosome $17 \mathrm{p} 11.2$ and three strong signals on the interphase chromosomes. However, SMS-REPspecific BACs also showed weaker hybridization signals in interphase analysis and metaphase spreads; these map to chromosomes 17p13.1, 17p12, 17q11.2, 17q12, 17q21.2, and 17q23.2 (Fig. 3).

Computational analysis also supported the existence of other SMS-REP-like sequences on chromosome 17. In concordance with FISH results, BLAST analysis revealed that $11-30$ $\mathrm{kb}$ fragments of SMS-REPs (Fig. 4) are localized on $17 \mathrm{p} 13.1$ ( 28 kb; RP11-500A7/AC008058; RP11-333E1/AC087500; CTD-2013F15/AC074339), 17p12 ( 11 kb; RP11-640I15/ AC005324), 17q11.2 ( 30 kb; RP11-218M11/AC011840; RP11-271K11/AC005562), 17q12 ( 11 kb; RP11-698P18/ AC067923; RP1191J4/AC003976), 17q21.2 ( 25 kb; RP11156A24/AC019349), and 17q23.2 ( 28 kb; RP11-767P9/ AC023352; RP11-178C3/AC005702).

A $>19$-kb fragment of average $>90 \%$ homology to a portion of SMS-REP, including the USP6 (TRE) gene, is located within the 17q11.2 BAC clone RP11-271K11/AC005562. This BAC clone also contains $\sim 85 \mathrm{~kb}$ of the neurofibromatosis type 1 LCR, proximal NF1-REP. In addition, we found that the distal NF1-REP on 17q24 (RP11-147L13; AC005332; Dorschner et al. 2000) maps directly adjacent to the breakpoint of the translocation $t(1 ; 17)$ associated with Russell-Silver syndrome (RSS; Dörr et al. 2001).

\section{Complex Genome Architecture in Proximal 17p}

Analysis of the DNA sequence within proximal 17p, including the SMS common deletion and CMT1A chromosome regions, revealed the presence of several genomic segments of sequence similarity $\geq 95 \%$ to SMS-REP and/or clones that directly flank SMS-REP (Fig. 5). Two LCRs, $\sim 90-k b$ LCR17pC and $\sim 150$-kb LCR17pD (also known as, proximal SMS-REP flanking sequences [PSFS]) were found to flank proximal SMS-REP and to be part of at least 410-kb LCR17pA, flanking proximal CMT1A-REP. LCR17pA has also been proposed to be responsible for the evolutionary chromosome translocation $4 ; 19$ in gorilla (Stankiewicz et al. 2001). In addition, an at least 210-kb segment LCR17pB within overlapping BAC clones RP11$448 \mathrm{D} 22$ and CTD-2145A24, proximally adjacent to the middle SMS-REP, was found to have $98 \%$ homology to the other portion of LCR17pA (Fig. 5). Interestingly, the breakpoints of an unusual chromosome deletion in two SMS patients have been identified to map within these LCR17p LCRs (our unpubl. data). The recognition that well-characterized chromosome 17 genomic duplications (SMS, CMT1A, and NF1) are further interspersed with previously unidentified homologous repeated sequences and that these additional LCRs are distributed elsewhere on this and other chromosomes underlines the overall complexity of the chromosome 17 genomic architecture.

\section{Evolutionary Studies}

Studies of LCRs involved in several genomic disorders suggest a recent evolutionary origin during primate speciation. In fact, the CMT1A-REP LCR in 17p12 (Pentao et al 1992) is present in human and chimpanzee but not in gorilla, orangutan, and other Old and New World monkeys (Kiyosawa and Chance 1996; Reiter et al. 1997; Boerkoel et al. 1999; Keller et al. 1999). We studied SMS-REP evolution during primate spe-

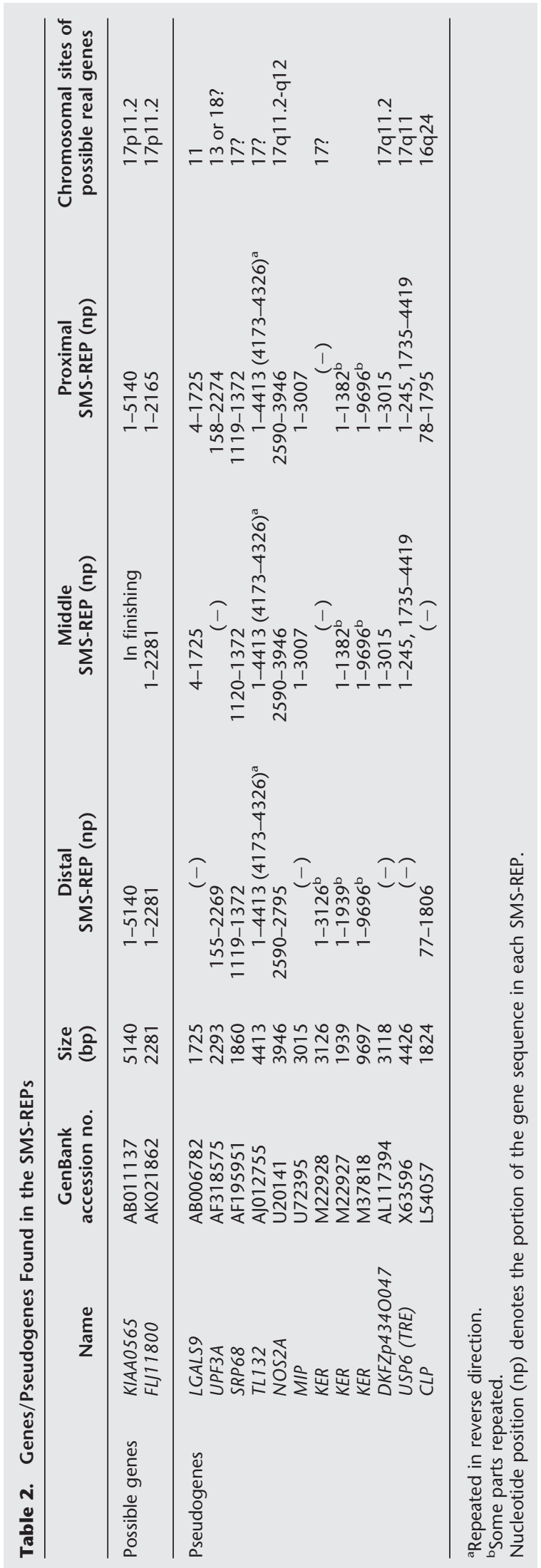




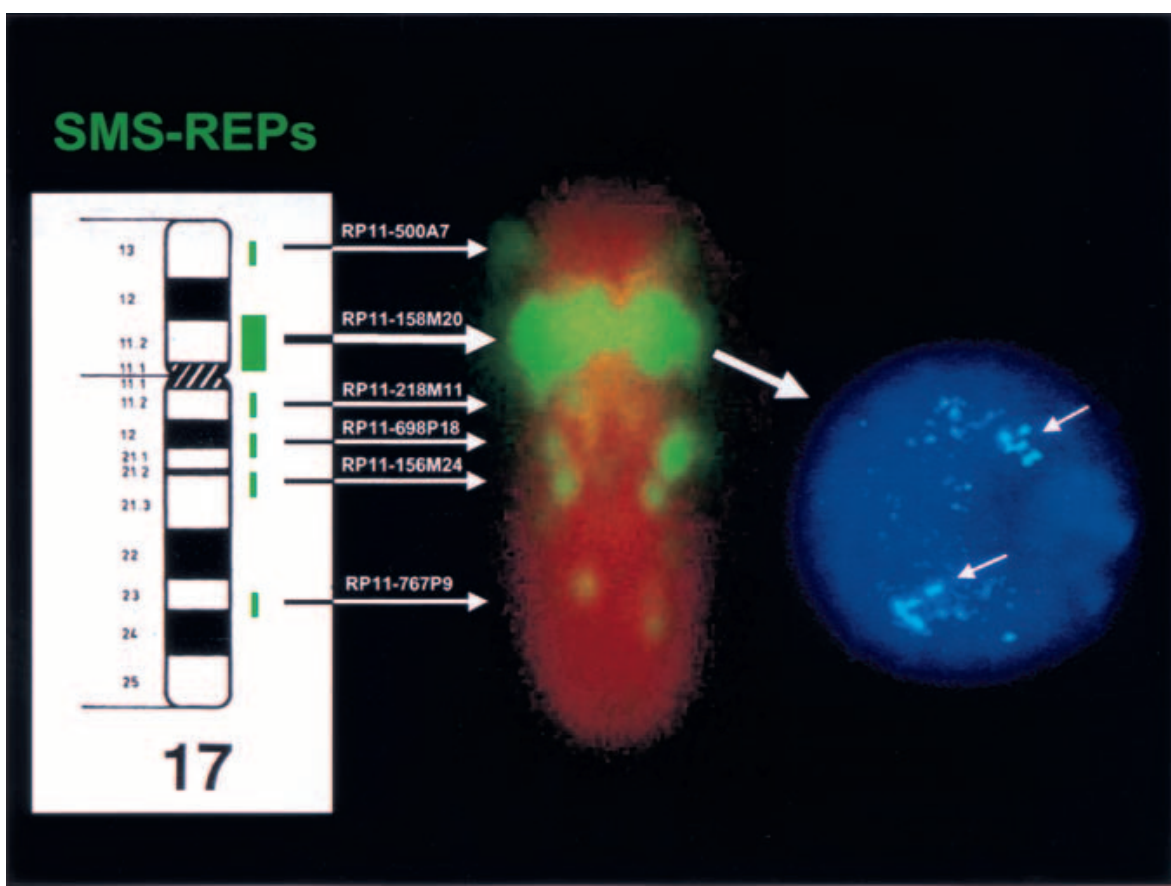

Figure 3 Human metaphase chromosome 17 and G2 interphase nucleus after fluorescence in situ hybridization (FISH) with SMS-REP-specific bacterial artificial chromosome (BAC) RP11-158M20. To the left is a human-chromosome-17 ideogram with the positions of hybridization signals (green) shown next to specific cytological bands. White horizontal arrows show specific locations of FISH signals with BACs containing the genomic segments listed above the arrows. To the right of the figure is a G2 interphase FISH analysis (the G2 phase of the nucleus was determined without an internal control probe). Note the three copies of SMS-REP (arrows in interphase nucleus) and SMS-REP-like sequences.

ciation by FISH analysis using human SMS-REP-specific BAC clone probes on different primate cell lines. One BAC from each SMS-REP (distal SMS-REP RP11-219A15/AC022596, middle SMS-REP RP11-158M20/AC023401, and proximal SMS-REP RP11-434D2/AC015818) was used in independent FISH experiments. As expected, the same result was obtained in each of the three separate experiments that used the different SMS-REP probes.

The characteristic fluorescence signal pattern after FISH with SMS-REP-containing BAC clones observed on human metaphase and interphase chromosomes 17 was visible on syntenic metaphase chromosomes of all great apes and Old World monkeys analyzed. The presence of three SMS-REP copies was confirmed by the analysis of the respective interphase nuclei (Fig. 6A). However, presumably due to reduced genomic sequence homology and thus lower hybridization efficiency on the metaphase and interphase chromosomes of New World squirrel monkey, the fluorescent signal after FISH with SMS-REP BAC was of significantly weaker intensity. Therefore it was difficult to determine unequivocally whether all three SMS-REP copies are present in this species.

To control for potential misinterpretation of absence of FISH signal secondary to decreased hybridization related to primary sequence divergence, we applied dual-color interphase FISH co-hybridizing SMS-REP BACs with differentially labeled human BAC clones that directly flank SMS-REP. In each of six possible combinations (two flanking unique BAC probes for each three SMS-REPs), nuclei from 50 cells were analyzed. We observed a yellow hybridization signal due to the overlapping of SMS-REP signal (green) and flanking clone signal (red; representative co-FISH in Fig. 6B). These data indicate the presence of all three repeats in squirrel monkey. Therefore, the age of the three SMS-REPs is assessed to be at least $\sim 40$ million years ago (Mya) - the time of divergence of New World monkeys from premonkeys (Kumar and Hedges 1998). To further delineate the origin of the SMS-REPs, we investigated evolutionarily older species, including pre-monkey lemur. Only weak unique SMS-region-specific sequence signals were visible. Based on the structure of the individual SMS-REPs and evolutionary investigations using primate cell lines, we propose that an SMS-REP progenitor copy was triplicated after the divergence of New World monkeys and pre-monkeys between $\sim 40-65$ Mya.

\section{DISCUSSION}

\section{Chromosome 17}

\section{Low-Copy Repeats}

Chromosome 17 contains several LCRs. It harbors two CharcotMarie-Tooth disease type $1 \mathrm{~A}$ CMT1A-REPs (17p12; Pentao et al. 1992; Reiter et al. 1997), three SMSREPs (17p11.2; Chen et al. 1997), and three neurofibromatosis type 1 NF1-REPs (17q11.2; Dorschner et al. 2000). These LCRs can serve as substrates for both intra- or interchromosomal NAHR, thus making the respective genomic region unstable and prone to chromosome rearrangements responsible for genomic diseases (for reviews, see Lupski 1998; Ji et al. 2000; Shaffer and Lupski 2000; Emanuel and Shaikh 2001; Stankiewicz and Lupski 2002). Ongoing work is identifying and characterizing additional LCRs, although their contribution to genomic disease is currently unknown.

The proximal SMS-REP spans $\sim 256 \mathrm{~kb}$ and is in the same orientation as the distal SMS-REP, which is shorter $(\sim 176 \mathrm{~kb})$ and devoid of some small repeat fragments. The middle SMSREP $(\sim 241 \mathrm{~kb})$ is inverted with respect to proximal and distal SMS-REPs. This architecture potentially explains why the common SMS deletions occur between proximal and distal SMS-REPs. The deletions and duplications resulting from NAHR require direct repeats as recombination substrates, whereas inverted repeat recombination substrates may lead to inversions (Lupski 1998)

We have identified recently five SMS patients with smaller-sized deletions who have rearrangements in which their proximal breakpoints map within or adjacent to the middle SMS-REP and the distal breakpoints within or adjacent to the distal SMS-REP (Bi et al. 2002; our unpubl. observations). A candidate genomic structure, which could be potentially responsible for this smaller deletion, is the inverted repeated sequences of $639 \mathrm{bp}$, including a part of the TL-132 gene (np 4173-4326 of AJ012755). This segment in the distal SMS-REP has the same orientation as that repeated in the 


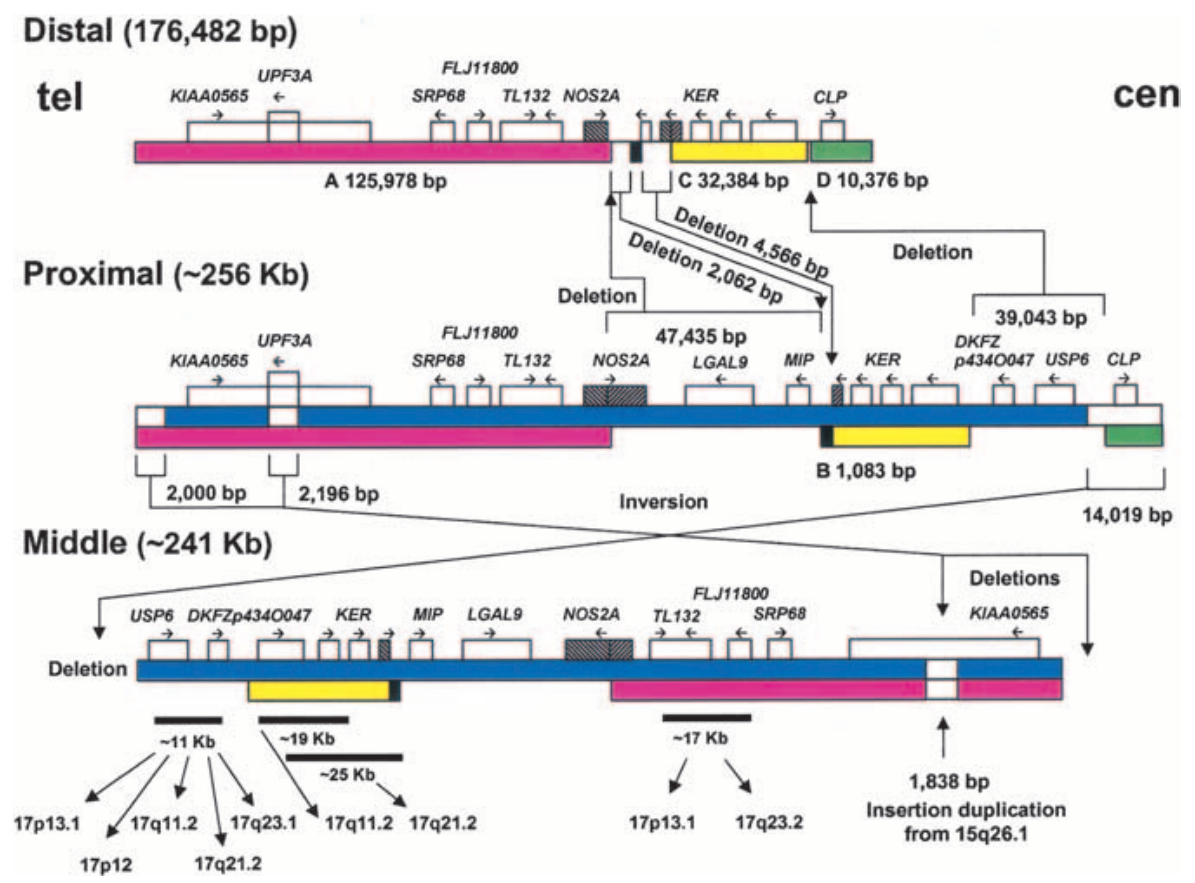

Figure 4 Sequence-based genomic structure of the SMS-REPs. There are four regions of sequence identity $>95 \%$ between the proximal and the distal SMS-REPs (A, B, C, and D). The A (red), B (black), and $C$ (yellow) sequence blocks have $>98 \%$ identity between distal and proximal REPs; the D regions (green) show $>95 \%$ identity. Blue represents the regions of homology between proximal and middle SMS-REPs. The proximal copy is the largest and is localized in the same orientations as the distal copy. The middle SMS-REP shows almost the same sequence and structure as the proximal copy except for two terminal deletions, an UPF3A gene interstitial deletion and a small ( $2 \mathrm{~kb})$ insertional duplication. However, it is inverted with respect to proximal and distal SMS-REPs. SMS-REP-specific CLP, TRE, and SRP cismorphisms (Table 1) were confirmed by DNA sequencing. Fourteen genes/pseudogenes were found and are summarized in Table 2. The two additional KER copies in distal SMS-REP represent repeated fragments of the KER pseudogenes, the accession numbers of which are given in Table 2. Crosshatched areas (NOS2A in the proximal and KER [M22927] in the distal) denote two genes spanning the high homology and nonhomology area between the distal and proximal, which suggest a three-step event for the hypothetical model of the evolution of the SMS-REPs (see text). At the bottom, the chromosome 17 distribution of fragments of SMS-REP, which constitutes a chromosome 17 low-copy repeat, LCR17, is shown. The above data were obtained through BLAST analysis of sequence database. polymorphisms involving large genomic regions mediated by olfactory receptor gene cluster LCR on chromosome $8 \mathrm{p}$ have been identified recently in $26 \%$ and $27 \%$ of populations of European and Japanese descent, respectively (Giglio et al. 2001; Matsumoto et al. 2001), in the parents of patients with Williams-Beuren (WBS) syndrome (33\%), and in some atypical WBS patients $(27 \%$; Osborne et al. 2001).

\section{Evolution of Low-Copy Repeats}

Previous hybridization studies suggested the absence of SMS-REP sequences in rodents (Chen et al. 1997; Probst et al. 1999). Here we provide evidence based on FISH analysis of primate cell lines that SMS-REP genomic duplication occurred after the divergence of New World monkeys and premonkey lemurs. Evolutionary studies of several different LCRs have shown that they arose recently, apparently during primate speciation (Kiyosawa and Chance 1996; Reiter et al. 1997; Boerkoel et al. 1999; Christian et al. 1999; Keller et al. 1999; Valero et al. 2000; Jenne et al. 2001; Inoue et al. 2001; Shaikh et al. 2001). A high sequence similarity but $<100 \%$ identity between LCRs appears to be responsible for genomic disorders (Lupski 1998) and suggests that one copy of the LCR is the progenitor and recent middle copy (np 81890-82528 and 69851-70489 in RP11219A15/AC022596 vs. np 135928-136566 and 147947148585 in RP11-158M20/AC023401), thus yielding a direct repeat. We also suggest that one of the parents of these 5 SMS patients may be a carrier of a paracentric inversion of the respective segments within $17 \mathrm{p} 11.2$, with one chromosome breakpoint involving middle SMS-REP. Similar chromosome

genomic duplication gave rise to its additional copies (Eichler 2001).

The two copies of CMT1A-REP have been shown to be absent from rodent species (Pentao et al. 1992). Both CMT1AREP copies were found in chimpanzee and human, whereas only the distal copy has been identified in gorilla, indicating that it must have been duplicated after the gorilla had diverged from a common human/ chimpanzee ancestor (Kiyosawa and Chance 1996; Reiter et al. 1997; Boerkoel et al. 1999; Keller et al. 1999; Inoue et al. 2001). Sequence analysis of CMT1A-REPs revealed that the distal copy is the original and is part of the COX10 gene. The proximal CMT1A-REP represents a duplicated copy of COX10 exon 6 and surrounding intronic sequences (Kiyosawa and Chance 1996; Murakami et al. 1997; Reiter et al. 1997; Boerkoel et al. 1999). Recently, it was shown that the CMT1A-REP insertional/duplica- 
A

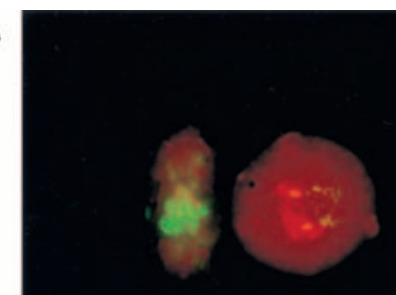

Pygmy chimp

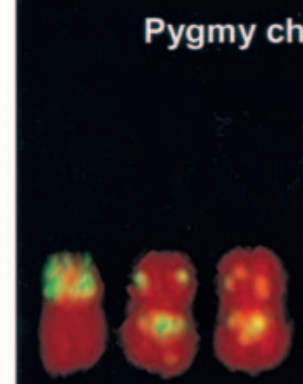

Gibbon

(1)

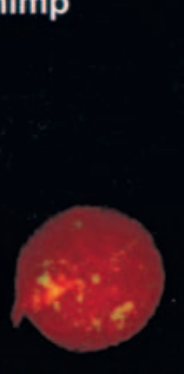

(1)

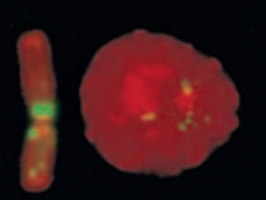

Gorilla

\section{B}

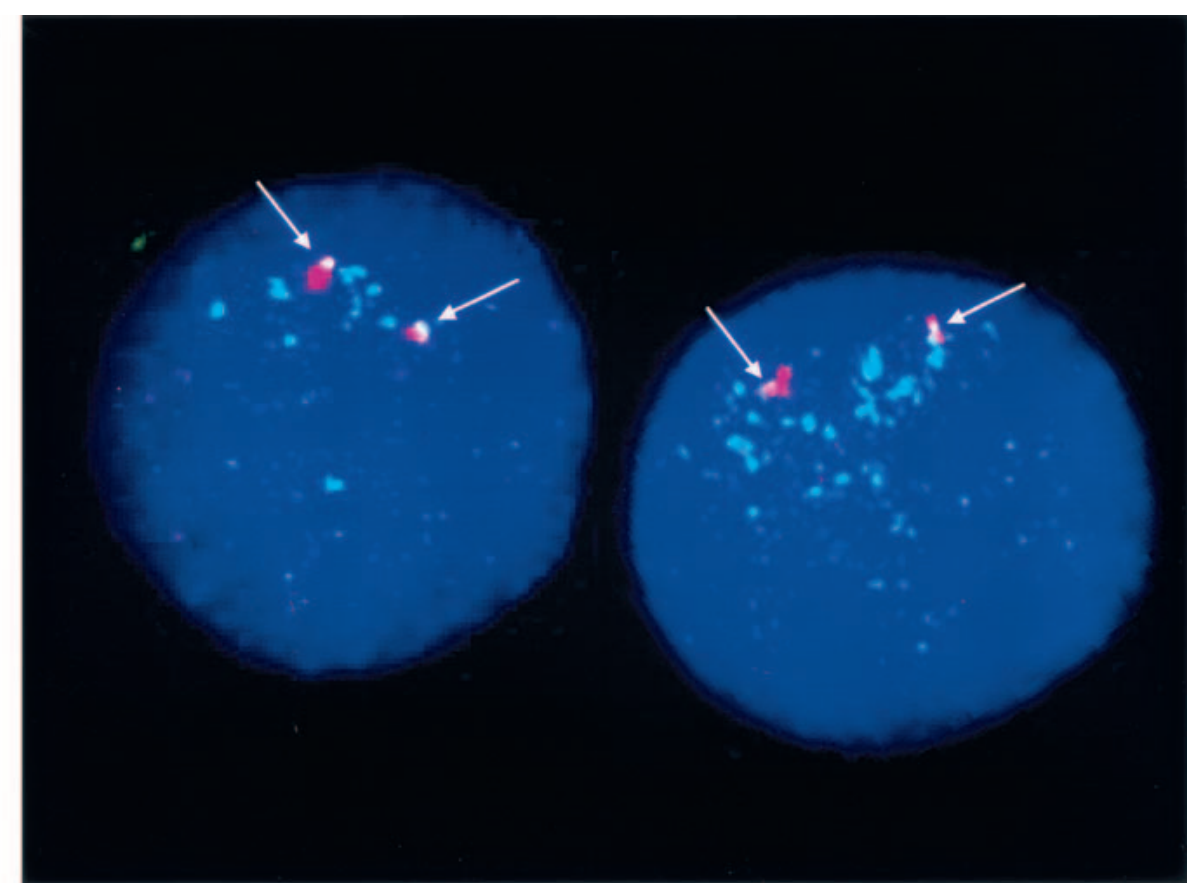

Figure 6 FISH analyses for evolutionary studies. (A) Metaphase and interphase cells of chimpanzee, gorilla, orangutan, gibbon, baboon, and rhesus after hybridization with SMS-REP bacterial artificial chromosome (BAC) RP11-158M20. (B) The interphase nuclei of New World squirrel monkey after cohybridization of differentially labeled SMS-REP-specific BAC (RP11-158M20) and a P1 artificial chromosome clone that directly flanks SMS-REP (RP1-178F10). Note the single yellow foci, indicating the $<100-k b$ physical vicinity of the clones. Similar results were obtained using five other clones directly flanking individual SMS-REPS, showing the presence of three copies of SMS-REPs.

tional event divided an ancestral gene, $A G I P$, into two genes: HREP and CDRT1. These findings illustrate the generation of new genes by DNA rearrangement during mammalian genome evolution (Kennerson et al. 1997; Inoue et al. 2001). Interestingly, sequences flanking proximal CMT1A-REP have

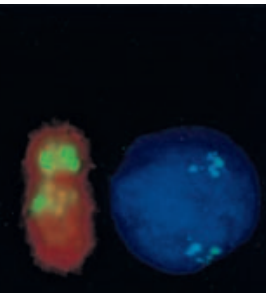

Orangutan been found to be duplicated on gorilla chromosome 19 at the breakpoints of the evolutionary reciprocal translocation $\mathrm{t}(4 ; 19)$ in gorilla, equivalent to human $\mathrm{t}(5 ; 17)$ (Stankiewicz et al. 2001).

The repeats flanking the Williams syndrome chromosome region were identified in chimpanzee, gorilla, orangutan, and gibbon but were absent in mice, indicating that the duplication event occurred after divergence of rodents and humans ( $\sim 80 \mathrm{Mya})$ but before the diversification of hominoids ( $15-20$ Mya; Valero et al. 2000). LCR-sequence comparisons show that block Bmid (common telomeric breakpoint) is probably the ancestral copy. Interestingly, repeat-like sequences were found on human chromosome $7 \mathrm{p} 22$ and $7 \mathrm{q} 22$ very close to the sites where the breakpoints of evolutionary inversions occurred. It was proposed, therefore, that these segmental duplications had been generated by the evolutionary inversions (DeSilva et al. 1999); however, it is possible these duplicated segments stimulated inversions. The LCR15s, implicated in the pathogenesis of PraderWilli and Angelman syndromes, were shown to be present in nonhuman primates, including New World monkeys, and only one copy in lemur, suggesting that the LCR duplication may have occurred $\sim 50$ Mya (Christian et al. 1999; Locke et al. 2001). The repeat block LCR15-BP3A was proposed to be an ancestral copy. Analysis of NF1-REPs and LCR22s suggests that their duplication may predate the divergence of the great apes $\sim 8$-9 Mya (Jenne et al. 2001) and New World monkeys $\sim 40$ Mya (Shaikh et al. 2001), respectively.

\section{A Model for the}

Evolution of the SMS-REPs Based on the structural information of three SMS-REPs, we propose a model to explain the evolution of the SMS-REPs. Evidence supporting this model includes the fact that two genes span the border of high- and low-homology areas between the proximal and the distal SMS-REPs, the NOS $2 A$ gene 
in the proximal, and the KER pseudogene (M22927) in the distal SMS-REP (crosshatched area in Fig. 4). A long sequence of the NOS $2 \mathrm{~A}$ gene is located across the border of the A region and its flanking area (A-B in Fig. 4) in the proximal SMS-REP, and a part of the gene in the A-B region is absent in the distal SMS-REP. Also the KER pseudogene (M22927) spans the C region and its flanking area (B-C in Fig. 4) in the distal SMS$\mathrm{REP}$, and a part of the gene in the $\mathrm{B}-\mathrm{C}$ region is absent in the proximal SMS-REP. Therefore, only parts of the NOS $2 A$ and the $K E R$ pseudogene remain in the distal and the proximal SMS-REP, respectively.

To explain these phenomena, we adopted the following three-step-event hypothesis (Fig. 7). Our data indicate that in the first step, $\sim 40-65$ Mya, a progenitor SMS-REP must have arisen in an ancient chromosome. Its structure was almost the same as the proximal SMS-REP of today but included flanking sequences on each side of the B region, as is the case of the distal SMS-REP. The distal SMS-REP resulted from the deletions of two large areas between the $\mathrm{A}$ and $\mathrm{B}$ regions and the $\mathrm{C}$ and D regions. Secondly, deletion of both flanking sequences of the $\mathrm{B}$ region in the progenitor resulted in the proximal SMS-REP. Finally, two terminal deletions (2 kb and $\sim 14 \mathrm{~kb})$ and one interstitial deletion $(\sim 2 \mathrm{~kb})$ associated with interchromosomal insertional duplication $(\sim 2 \mathrm{~kb})$, along with an inversion, generated the middle SMS-REP (Fig. 4).

Based on the structure of the identified LCRs flanking the proximal SMS-REP and proximal CMT1A-REP and adjacent to the middle SMS-REP, we suggest that before the origin of SMSREPs, an at least $410 \mathrm{~kb}$ chromosome segment flanking the proximal CMT1A-REP (LRC17pA) must have undergone partial segmental duplication in an ancestral chromosome syntenic to the proximal HSA 17p, thus further supporting that segmental duplications have accompanied karyotype evolution in primates.

\section{Conclusion}

Our molecular analysis of the SMS-REP LCRs reveals a complex structure consisting of at least 14 genes/pseudogenes. There is

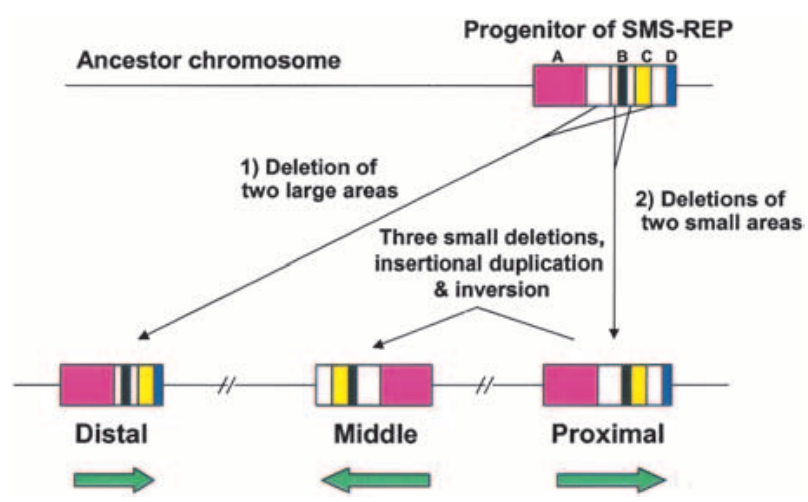

Figure 7 Hypothetical model for evolution of SMS-REPs. Our data indicate that in the first step, a progenitor SMS-REP must have arisen in an ancient chromosome. Its structure was almost the same as the proximal SMS-REP at the present time, but included the B region flanking sequences on both sides similar to the distal SMS-REP. The distal SMS-REP resulted from the deletions of two large areas between the $A$ and $B$, and $C$ and $D$ regions. Secondly, deletion of both flanking sequences of the $B$ region in the progenitor resulted in the proximal SMS-REP. Finally, two terminal deletions and one interstial deletion involving the UPF3A gene accompanied by interchromosomal insertional duplication together with an inversion generated the middle SMS-REP. remarkable preservation of sequence homology, $>160 \mathrm{~kb}$ of $\sim 98 \%$ identity, providing a sizable substrate for homologous recombination. Portions of the SMS-REP are present on $17 \mathrm{q}$, constituting a chromosome 17 low-copy repeat (LCR17) similar to what has been identified on chromosome 22 (Dunham et al. 1999), whereas some copies of its gene constituents appear to map to other chromosomes. Like other LCRs that mediate DNA rearrangements responsible for genomic disorders, SMS-REP appears to have evolved during primate speciation. Further analyses of proximal chromosome 17p suggest even more complex genome architecture. Why and how large homology segments are preserved in the human genome is not immediately obvious. Nevertheless, in-depth analyses of such LCRs is essential for further determining the higher order architecture of the human genome and to predict regions of susceptibility for rearrangements leading to chromosome imbalance.

\section{METHODS}

PCR

PCR was performed with extracted BAC DNA using each of the following primer sets: CLP (TCTGTAAACTGTCTGAGTGCAGAG/CGTCTGCACC-ACACAATCAAAAGG), 3'TRE (A C A G G T A G C A C A A T C T A C T A A / T T C T G T G T T T ACTTGTATGAGG), SRP (GGAAGCACTTGCTGTCATCC/ GCCCAGGCCAAATGG-CCCTGG), KER (CTCTGCTCTGACCCTCTA/AGCCCTGATCCTTGGGGTCCAG), SHMT (TGGACGCACATTTGTCCTAC/CAGGGACCTGCAGAACTGAC), R193 (GGCAGCTCAGGGTGAGCTCTTC/TATTGGCCTTAAATGCATCTCA), RP11-92B11 reverse end (GGCTGAATGTTTTCCCACAT/AAGGAGATGAAAGGCAGCAA), RP11315G18 reverse end (CTCCACCGAAAAGCCTACAG/ TGCCCTGGAGTTACA-AGATG), TOP3 (TGGTTGC TGTTAGCAGAGGA/CCTTGCATTACACCGTCCTT), RP11484D23 reverse end (AAGTCTCTGGAGCTCTCATTCA/ CCCAGGCACACTA-AACCATT), RP5-836L9 5' end (ACCTCAGAGGCTACCTCACG/CCAAAGACAG CTATCCACTGC), RP11-121A13 forward end (GGTTGTCTGGGCTTGGTAGA/ TG AGTGCCAGCTAAGTGCTC), and D17S959 (TCAGATTGAACTCTCGGTAT/GCTG AC ACAGGCAATG).

PCR reactions were performed on a final volume of 25 $\mu \mathrm{L}$, using $0.7 \mathrm{U}$ of Ampli-Taq polymerase in $200 \mu \mathrm{M}$ each of dNTPs; $1 \times$ GeneAmp PCR buffer $(10 \mathrm{mM}$ Tris- $\mathrm{HCl}$ at pH8.3 and $25^{\circ} \mathrm{C} ; 50 \mathrm{mM} \mathrm{KCL} ; 1.5 \mathrm{mM} \mathrm{MgCl} 2 ; 0.001 \%$ [w/v] gelatin) and 10 pmoles of each primer. PCR conditions were $95^{\circ} \mathrm{C}$ for $5 \mathrm{~min} ; 35 \mathrm{cycles}$ of $94^{\circ} \mathrm{C}$ for $30 \mathrm{sec}, 55^{\circ} \mathrm{C}$ for $30 \mathrm{sec}$, and $72^{\circ} \mathrm{C}$ for $1 \mathrm{~min}$, followed by $72^{\circ} \mathrm{C}$ for $7 \mathrm{~min}$. The products were visualized on $2 \%$ agarose gels.

\section{BAC Library Screening}

We screened segments 1 and $2(11.8 \times)$ of RPCI-11 BAC library (BACPAC Resource Center, Children's Hospital Oakland Research Institute; www.chori.org/bacpac) using CLP, SRP, and $S H M T$ gene probes. CLP probes were cDNA probe $(1.1 \mathrm{~kb}$ HindIII fragment of the cDNA clone 41G7A), overgo (Cai et al. 1998) oligonucleotide CLP1 (CGGCGATGGCCACCAAGA/ GAAGCCTCTTTGTCGATCTTGGTG), and overgo CLP2 (CCAAAGCGACAAGATCGT/CGGGCCTCTCTCCCTAACGATCTT); SRP probe was the PCR products amplified by SRP primer sets; SHMT probe was overgo (GAAGACTACACAGGGCCTTCCTCA/AAGCGACAGGCTTAAGTGAGGAAG). Hybridizations were performed according to the previously described methods (www.chori.org/bacpac; Cai et al. 1998)

BAC end sequences of the assigned clones were obtained from TIGR (http://www.tigr.org). We also identified several candidate clones from BLAST searches (http://www.ncbi.nlm.nih.gov/BLAST) using the BAC end sequences. We checked the extent of the assigned clones by PCR for STSs and BAC ends. 


\section{BAC Sequencing and Sequence Analysis}

BAC and PAC clone sequencing was performed after generation of $\mathrm{m} 13$ and/or plasmid subclone libraries. Individual clones were either sequenced to fourfold coverage (draft quality) and then further sequenced to greater than eightfold coverage or sequenced immediately to greater than eightfold coverage. After greater than eightfold coverage and assembly, directed finishing techniques were applied to determine the sequences of the remaining gaps. All clones were sequenced and assembled independent of each other and then analyzed to confirm their placement in the tiling paths and determine their degree of overlap with neighboring clones. Specific sequencing and finishing procedures were performed as summarized (International Human Genome Sequencing Consortium 2001).

Regional assemblies for each SMS-REP were constructed following BLAST searches against the high-throughput and the nonredundant sequence database (http://www. ncbi.nlm.nih.gov/blast/) and assembled using the Sequencher software (Gene Codes). Genes and transcripts were identified by a database search of the genomic sequences using the BLAST nonredundant database (Altschul et al. 1997).

\section{Fingerprint Analysis}

BAC clones identified following library screens with CLP and SMS-REP markers were fingerprinted and analyzed as described by Marra et al. (1997). Purified BAC DNAs were digested with HindIII, electrophoresed on 1\% agarose gels, and stained with SYBR Green I (Roche Diagnostics); then gel images were recorded using a FluorImager SI (Molecular Dynamics). Relative mobility files of observed bands were created using Image (http://www.sanger.ac.uk/Software/Image); then fingerprint data were stored and analyzed using FPC (http:// www.sanger.ac.uk/Software/fpc). Clones were grouped into fingerprint contigs as described by Marra et al. (1997), with every internal clone requiring having all of its fragments shared with overlapping clones.

\section{Southern Blotting}

Southern hybridization was performed as described by Chen et al. (1997). The target DNAs (human genomic DNA, SMSREP specific YAC and BAC clones) were cut with various restriction enzymes (HindIII, XbaI, PstI, PvuII, RsaI, TaqI, BglII, XhoI, BamHI, EcoRI KpnI, MspI, and DraI) and hybridized with $C L P$ cDNA probe and the PCR products for TRE and SRP.

\section{Fluorescence In Situ Hybridization}

FISH was performed on metaphase and interphase cells of transformed peripheral blood lymphoblasts and skin fibroblasts according to a modified procedure of Shaffer et al. (1997). Briefly, $1 \mu \mathrm{g}$ of isolated DNA of BAC/PAC clones: RP11-98L14 (proximally adjacent to the proximal SMS-REP), RP11-434D2 (proximal SMS-REP), RP5-836L9 (distally adjacent to the proximal SMS-REP), RP11-28B23 (proximally to the middle SMS-REP), RP11-158M20 (middle SMS-REP), RP1-178F10 (distal to the middle SMS-REP), RP11-416I2 (proximal to the distal SMS-REP), and RP11-219A15 (distal SMS-REP), and RP11-209J20 (distally adjacent to the distal SMS-REP) was labeled by nick-translation reaction using biotin- (Life Technologies-GibcoBRL) or digoxigenin- (Boehringer Mannheim) labeled nucleotides. Biotin was detected with FITC-avidin DCS (fluoresces green; Vector Labs) and digoxigenin was detected with rhodamine-anti-digoxigenin antibodies (fluoresces red; Sigma). Chromosomes were counterstained with DAPI diluted in Vectashield antifade (Vector Labs). Cells were viewed under a Zeiss Axioskop fluorescence microscope equipped with appropriate filter combinations. Monochromatic images were captured and pseudocolored using MacProbe 4.2.2/Power Macintosh G4 system (Perceptive Scientific Instruments, Inc.).

\section{Cell Lines}

The human and primate lymphoblastoid cell lines and fibroblasts were grown and harvested using standard methods. The nonhuman-primate-immortalized Epstein-Barr virus stimulated cell lines of lowland gorilla (Gorilla gorilla, CRL 1854), orangutan (Pongo pygmaeus), gibbon (Hylobates lar, TIB-201), New World monkey baboon (Papio hamadryas), Rhesus monkey (Macaca mulatta), and New World squirrel monkey (Saimiri sciureus) were purchased from the American Type Culture Collection (ATCC; http://www.atcc.org/). African green monkey (Cercopithecus aethiops) fibroblasts were also obtained from ATCC. The lemur (Varecia variegates rubber) fibroblasts were obtained from the Center for Reproduction of Endangered Species, Zoological Society of San Diego, (http://www.sandiegozoo.org/conservation/ cres_home.html) and the pygmy chimp (Pan paniscus) lymphoblast sample was kindly provided by Dr. D. Nelson from Baylor College of Medicine.

\section{ACKNOWLEDGMENTS}

We appreciate the critical reviews of Drs. B. Bejiani, N. Katsanis, L. Potocki, L. Reiter, and L.G. Shaffer and the excellent technical assistance of M. Withers. We thank Eric Lander for his interest and support. S.-S.P. is supported by Seoul National University Hospital. This study was supported in part by grants from the Muscular Dystrophy Association, the National Institute of Neurological Disorders and Stroke (R01 NS27042), the National Institute of Child Health and Human Development (PO1 HD39420), and the National Human Genome Research Institute (U54 HG02045).

The publication costs of this article were defrayed in part by payment of page charges. This article must therefore be hereby marked "advertisement" in accordance with 18 USC section 1734 solely to indicate this fact.

\section{REFERENCES}

Altschul, S.F., Madden, T.L., Schäffer, A.A., Zhang, J., Zhang, Z., Miller, W., and Lipman, D.J. 1997. Gapped BLAST and PSI-BLAST: A new generation of protein database search programs. Nucleic Acids Res. 25: 3389-3402.

Bi, W., Yan, J., Stankiewicz, P., Park, S.-S., Walz, K., Boerkoel, C.F., Potocki, L., Shaffer, L.G., Devriendt, K., Nowaczyk, M.I.M., Inoue, K., and Lupski, J.R. 2002. Genes in the Smith-Magenis syndrome critical deletion interval on chromosome $17 \mathrm{p} 11.2$ and the syntenic region of mouse. Genome Res. 12: 713-728.

Boerkoel, C.F., Inoue, K., Reiter, L.T., Warner, L.E., and Lupski, J.R. 1999. Molecular mechanisms for CMT1A duplication and HNPP deletion. Ann. N.Y. Acad. Sci. 883: 22-35.

Cai, W.W., Reneker, J., Chow, C.-W., Vaishnav, M., and Bradley, A. 1998. An anchored framework BAC map of mouse chromosome 11 assembled using multiplex oligonucleotide hybridization. Genomics 54: 387-397.

Chen, K.-S., Manian, P., Koeuth, T., Potocki, L., Zhao, Q., Chinault, A.C., Lee, C.C., and Lupski, J.R. 1997. Homologous recombination of a flanking repeat gene cluster is a mechanism for a common contiguous gene deletion syndrome. Nat. Genet. 17: 154-163.

Christian, S.L., Fantes, J.A., Mewborn, S.K., Huang, B., and Ledbetter, D.H. 1999. Large genomic duplicons map to sites of instability in the Prader-Willi/Angelman syndrome chromosome region (15q11-q13). Hum. Mol. Genet. 8: 1025-1037.

DeSilva, U., Massa, H., Trask, B.J., and Green, E.D. 1999. Comparative mapping of the region of human chromosome 7 deleted in Williams syndrome. Genome Res. 9: 428-436.

Dörr, S., Midro, A.T., Färber, C., Giannakudis, J., and Hansmann, I. 2001. Construction of a detailed physical and transcript map of the candidate region for Russell-Silver syndrome on chromosome 17q23-q24. Genomics 71: 174-181.

Dorschner, M.O., Sybert, V.P., Weaver, M., Pletcher, B.A., and Stephens, K. 2000. NF1 microdeletion breakpoints are clustered at flanking repetitive sequences. Hum. Mol. Genet. 9: 35-46.

Dunham, I., Shimizu, N., Roe, B.A., Chissoe, S., Hunt, A.R., Collins, J.E., Bruskiewich, R., Beare, D.M., Clamp, M., Smink, L.J., et al. 1999. The DNA sequence of human chromosome 22. Nature 402: 489-495. 
Eichler, E.E. 2001. Recent duplication, domain accretion and the dynamic mutation of the human genome. Trends Genet. 17: 661-669.

Emanuel, B.S. and Shaikh, T.H. 2001. Segmental duplications: An "expanding" role in genomic rearrangements. Nat. Rev. Genet. 2: 791-800.

Fioretos, T., Strömbeck, B., Sandberg, T., Johansson, B., Billström, R., Borg, A., Nilsson, P.-G., Van Den Berghe, H., Hagemeijer, A. Mitelman, F., et al. 1999. Isochromosome 17q in blast crisis of chronic myeloid leukemia and in other hematologic malignancies is the result of clustered breakpoints in $17 \mathrm{p} 11$ and is not associated with coding TP53 mutations. Blood 4: 225-232.

Frühwald, M.C., O'Dorisio, M.S., Dai, Z., Rush, L.J., Krahe, R., Smiraglia, D.J., Pietsch, T., Elsea, S.H., and Plass, C. 2001. Aberrant hypermethylation of the major breakpoint cluster region in $17 \mathrm{p} 11.2$ in medulloblastomas but not supratentorial PNETs. Genes Chromosomes Cancer 30: 38-47.

Giglio, S., Broman, K.W., Matsumoto, N., Calvari, V., Gimelli, G., Neumann, T., Ohashi, H., Voullaire, L., Larizza, D., Giorda, R., et al. 2001. Olfactory receptor-gene clusters, genomic-inversion polymorphisms, and common chromosome rearrangements. Am J. Hum. Genet. 68: 874-883.

Inoue, K., Dewar, K., Katsanis, N., Reiter, L.T., Lander, E.S., Devon, K.L., Wyman, D.W., Lupski, J.R., and Birren, B. 2001. The 1.4-Mb CMT1A duplication/HNPP deletion genomic region reveals unique genome architectural features and provides insights into the recent evolution of new genes. Genome Res. 11: 1018-1033.

International Human Genome Sequencing Consortium. 2001. Initial sequencing and analysis of the human genome. Nature 409: 860-921.

Jenne, D.E., Tinschert, S., Reimann, H., Lasinger, W., Thiel, G., Hameister, H., and Kehrer-Sawatzki, H. 2001. Molecular characterization and gene content of breakpoint boundaries in patients with neurofibromatosis type 1 with $17 \mathrm{q} 11.2$ microdeletions. Am. J. Hum. Genet. 69: 516-527.

Ji, Y., Eichler, E.E., Schwartz, S., and Nicholls, R.D. 2000. Structure of chromosomal duplicons and their role in mediating human genomic disorders. Genome Res. 10: 597-610.

Juyal, R.C. Kuwano, A., Kondo, I., Zara, F., Baldini, A., and Patel, P.I. 1996. Mosaicism for del(17)(p11.2p11.2) underlying the Smith-Magenis syndrome. Am. J. Med. Genet. 66: 193-196.

Keller, M.P., Seifried, B.A., and Chance, P.F. 1999. Molecular evolution of the CMT1A-REP region: A human- and chimpanzee-specific repeat. Mol. Biol. Evol. 16: 1019-1026.

Kennerson, M.L., Nassif, N.T., Dawkins, J.L., DeKroon, R.M., Yang, J.G., and Nicholson, G.A. 1997. The Charcot-Marie-Tooth binary repeat contains a gene transcribed from the opposite strand of a partially duplicated region of the COX10 gene. Genomics 46: 61-69.

Kiyosawa, H. and Chance, P.F. 1996. Primate origin of the CMT1A-REP repeat and analysis of a putative transposon-associated recombinational hotspot. Hum. Mol. Genet. 5: 745-753.

Kumar, S. and Hedges, S.B. 1998. A molecular timescale for vertebrate evolution. Nature 392: 917-920.

Locke, D.P., Yavor, A.M., Lehoczky, J., Chang, J., Dewar, K., Zhao, S., Nichols, R.D., Schwartz, S., and Eichler, E.E. 2001. Structure and evolution of genomic duplication in 15q11-q13. Am. J. Hum. Genet. 69: 179, Suppl. 1, Abstract 17.

Lupski, J.R. 1998. Genomic disorders: Structural features of the genome can lead to DNA rearrangements and human disease traits. Trends Genet. 14: 417-422.

Marra, M.A., Kucaba, T.A., Dietrich, N.L., Green, E.D., Brownstein, B., Wilson, R.K., McDonald, K.M., Hillier, L.W., McPherson, J.D., and Waterston, R.H. 1997. High throughput fingerprint analysis of large-insert clones. Genome Res. 7: 1072-1084.

Matsumoto, N., Harada, N., Giglio, S., Kuroiwa, K., Ledbetter, D.H., and Niikawa, N. 2001. Inverted low copy repeats and a common 8p23 inversion polymorphism. Am. J. Hum. Genet. 69: 789, Suppl. 1, Abstract 318

Mazzarella, R. and Schlessinger, D. 1998. Pathological consequences of sequence duplications in the human genome. Genome Res. 8: $1007-1021$.

Murakami, T., Reiter, L.T., and Lupski, J.R. 1997. Genomic structure and expression of the human heme A:farnesyltransferase (COX10) gene. Genomics 42: 161-164.

Osborne, L.R., Li, M., Pober, B., Chitayat, D., Bodurtha, J., Mandel A., Costa, T., Grebe, T., Cox, S., Tsui, L.-C., et al. 2001. A 1.5 million-base pair inversion polymorphism in families with Williams-Beuren syndrome. Nat. Genet. 29: 321-325

Otaño-Joos, M., Mechtersheimer, G., Ohl, S., Wilgenbus, K.K., Scheurlen, W., Lehnert, T., Willeke, F., Otto, H.F., Lichter, P., and Joos, S. 2000. Detection of chromosomal imbalances in leiomyosarcoma by comparative genomic hybridization and interphase cytogenetics. Cytogenet. Cell Genet. 90: 86-92.

Pentao, L., Wise, C.A., Chinault, A.C., Patel, P.I., and Lupski, J.R. 1992. Charcot-Marie-Tooth type 1A duplication appears to arise from recombination at repeat sequences flanking the $1.5 \mathrm{Mb}$ monomer unit. Nat. Genet. 2: 292-300.

Potocki, L., Chen, K.-S., Park, S.-S., Osterholm, D.E., Withers, M.A., Kimonis, V., Summers, A.M., Meschino, W.S., Anyane-Yeboa, K., Kashork, C.D., et al. 2000. Molecular mechanism for duplication $17 \mathrm{p} 11.2-$ The homologous recombination reciprocal of the Smith-Magenis microdeletion. Nat. Genet. 24: 84-87.

Probst, F.J., Chen, K.-S., Zhao, Q., Wang, A., Friedman, T.B., Lupski, J.R., and Camper, S.A. 1999. A physical map of the mouse shaker-2 region contains many of the genes commonly deleted in Smith-Magenis syndrome (del17p11.2p11.2). Genomics 55: 348-352.

Reiter, L.T., Murakami, T., Koeuth, T., Gibbs, R.A., and Lupski, J.R. 1997. The human COX10 gene is disrupted during homologous recombination between the $24 \mathrm{~kb}$ proximal and distal CMT1A-REPs. Hum. Mol. Genet. 6: 1595-1603.

Scheurlen, W.G., Schwabe, G.C., Seranski, P., Joos, S., Harbott, J., Metzke, S., Döhner, H., Poustka, A., Wilgenbus, K., and Haas, O.A. 1999. Mapping of the breakpoints on the short arm of chromosome 17 in neoplasms with an $\mathrm{i}(17 \mathrm{q})$. Genes Chromosomes Cancer 25: 230-240.

Shaffer, L.G. and Lupski, J.R. 2000. Molecular mechanisms for constitutional chromosomal rearrangements in humans. Annu. Rev. Genet. 34: 297-329.

Shaffer, L.G., Kennedy, G.M., Spikes, A.S., and Lupski, J.R. 1997 Diagnosis of CMT1A duplications and HNPP deletions by interphase FISH: Implications for testing in the cytogenetics laboratory. Am. J. Med. Genet. 69: 325-331.

Shaikh, T.H., Kurahashi, H., and Emanuel, B.S. 2001. Evolutionarily conserved low copy repeats (LCRs) in 22q11 mediate deletions, duplications, translocations, and genomic instability: An update and literature review. Genet. Med. 3: 6-13.

Stankiewicz, P. and Lupski, J.R. 2002. Genome architecture, rearrangements and genomic disorders. Trends Genet. 18: 74-82.

Stankiewicz, P., Park, S.-S., Inoue, K., and Lupski, J.R. 2001. The evolutionary chromosome translocation 4;19 in Gorilla gorilla is associated with microduplication of the chromosome fragment syntenic to sequences surrounding the human proximal CMT1A-REP. Genome Res. 11: 1205-1210.

Tarkkanen, M., Karhu, R., Kallioniemi, A., Elomaa, I., Kivioja, A.H., Nevalainen, J., Böhling, T., Karaharju, E., Hyytinen, E., Knuutila, S., et al. 1995. Gains and losses of DNA sequences in osteosarcomas by comparative genomic hybridization. Cancer Res. 55: 1334-1338.

Valero, M.C., de Luis, O., Cruces, J., and Perez Jurado, L.A. 2000. Fine-scale comparative mapping of the human 7q11.23 region and the orthologous region on mouse chromosome 5G: The low-copy repeats that flank the Williams-Beuren syndrome deletion arose at breakpoint sites of an evolutionary inversion(s). Genomics 69: 1-13.

Zori, R.T., Lupski, J.R., Heju, Z., Greenberg, F., Killian, J.M., Gray, B.A., Driscoll, D.J., Patel, P.I., and Zackowski, J.L. 1993. Clinical, cytogenetic, and molecular evidence for an infant with Smith-Magenis syndrome born from a mother having a mosaic 17p11.2p12 deletion. Am. J. Med. Genet. 47: 504-511.

\section{WEB SITE REFERENCES}

http://www.atcc.org/; The American Type Culture Collection (ATCC) web site.

http://www.ncbi.nlm.nih.gov/; NCBI web site.

http://www.sanger.ac.uk/Software/Image; Web site for Image software.

http://www.sanger.ac.uk/Software/fpc; The Wellcome Trust Sanger Institute.

http://www.tigr.org; TIGR.

http://www.sandiegozoo.org/conservation/cres_home.html; Center for Reproduction of Endangered Species, Zoological Society of San Diego, San Diego, CA.

www.chori.org/bacpac; Children's Hospital Oakland - BAC-PAC Resources.

Received December 18, 2001; accepted in revised form March 15, 2002.

\section{Genome Research}




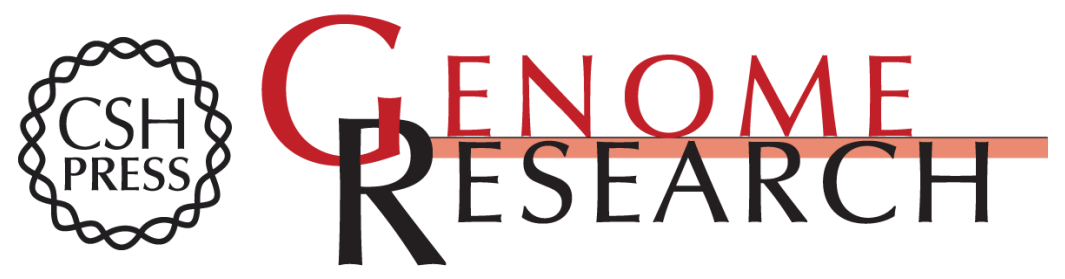

\section{Structure and Evolution of the Smith-Magenis Syndrome Repeat Gene Clusters, SMS-REPs}

Sung-Sup Park, Pawel Stankiewicz, Weimin Bi, et al.

Genome Res. 2002 12: 729-738

Access the most recent version at doi:10.1101/gr.82802

References This article cites 44 articles, 8 of which can be accessed free at:

http://genome.cshlp.org/content/12/5/729.full.html\#ref-list-1

\section{License}

Email Alerting Receive free email alerts when new articles cite this article - sign up in the box at the Service top right corner of the article or click here.

\section{Affordable, Accurate Sequencing.}

To subscribe to Genome Research go to: https://genome.cshlp.org/subscriptions 